\title{
SENAM HAMIL DENGAN LAMANYA PERSALINAN KALA II PADA IBU BERSALIN DI PUSKESMAS SAMATA DAN PUSKESMAS MONCOBALANG KABUPATEN GOWA
}

\section{Pregnant Exercise with the Duration Kala II in Laboring Mothers at Samata and Moncobalang Public Health Center of Gowa District}

\author{
Agustina Ningsi, Nurjaya, Maria Sonda \\ Poltekkes Kemenkes Makassar
}

\begin{abstract}
ABSTRAK
Lamanya proses persalinan dapat dipengaruhi oleh tiga hal yaitu tenaga, jalan lahir dan janin. Sampai saat ini yang dapat dikendalikan adalah masalah tenaga atau power, yaitu ditingkatkan dengan senam hamil. Senam hamil dapat membantu persalinan sehingga ibu dapat melahirkan tanpa kesulitan, serta menjaga ibu dan bayi sehat setelah melahirkan (Ida, 2012). Penelitian ini menggunakan desain retrospektif kohort. Populasi dalam penelitian ini adalah semua ibu bersalin di Wilayah Kerja Puskesmas Samata dan Puskesmas Moncobalang Kabupaten Gowa, menggunakan rumus Lemeshow didaptkan jumlah sampel 60 orang dengan teknik pengambilan sampel yaitu purposive sampling. Hasil Uji Chi-square dan nilai Risk Ratio pada penelitian ini didapatkan hasil nilai $p=0,079$ dan nilai $\mathrm{RR}=1,143$ yang artinya umur bukan merupakan faktor risiko cepatnya proses persalinan kala II pada ibu bersalin. Nilai $p=0,006$ dan nilai RR= 2,918 yang artinya ibu multipara 3 kali lipat lebih cepat proses persalinan kala II-nya. Nilai $p=0,813$ dan nilai $R R=1,133$, artinya berat badan lahir bukan merupakan faktor risiko cepatnya proses persalinan kala II pada ibu bersalin. Nilai $p=0,001$ dan nilai $\mathrm{RR}=5,000$, artinya ibu yang melakukan senam hamil 5 kali lipat lebih cepat proses persalinan kala II-nya dari pada ibu yang tidak melakukan senam hamil. Dari penjelasan di atas dapat disimpulkan bahwa variabel senam hamil merupakan variabel yang memiliki hubungan paling dominan dengan lamanya persalinan kala II dengan nilai $R R=5,000$.
\end{abstract}

Kata Kunci: Umur, Paritas, Berat Badan Lahir, Senam Hamil, Kala II.

\section{ABSTRACT}

The length of the delivery process can be influenced by three things, namely energy, birth canal and fetus. Until now, what can be controlled is the problem of power or power, which is increased by pregnant gymnastics. Pregnant gymnastics can help deliveries so that mothers can give birth without difficulty, as well as keep mothers and babies healthy after giving birth (Ida, 2012). This study used a design retrospective cohort. The population in this study were all mothers giving birth in the Samata and Moncobalang Public Health Center of Gowa District. Using the formula, a Lemeshow total sample of 60 people was obtained with the sampling technique, namely purposive sampling. The results of the test Chi-square and the value of the risk ratio in this study showed that the results of the $p$ value $=0,079$ and the value of $R R=1,143$, which means that age is not a risk factor for the fast process of the second stage labor in the mother giving birth. Value of $p=$ 0,006 and the value of $R R=2,918$, which means mother multipara 3 times faster process its second stage of labor. Value $p=0,813$ and the value of $R R=1,133$, meaning that birth weight is not a risk factor in the speed of the second stage of labor on maternal. Value of $p=0,001$ and value of $R R=5,000$, meaning that mothers who do pregnancy exercise 5 times faster the process of childbirth stage II than mothers who do not pregnant exercise. From the explanation above, it can be concluded that the variable pregnant exercise is the variable that has the most dominant relationship with the length of the second stage of labor with a risk ratio of 5,000 .

Keywords: Age, Parity, Birth Weight, Pregnant Exercise, Kala II.

\section{PENDAHULUAN}

Kehamilan merupakan proses yang alamiah, walaupun tidak dipungkiri dalam beberapa kasus mungkin terjadi komplikasi sejak awal karena kondisi tertentu atau terjadi di kemudian hari sehingga mengakibatkan tingginya morbiditas dan mortalitas terhadap ibu (Kuswanti, 2014).

Berdasarkan data Survei Demografi Kesehatan Indonesia (SDKI) 2012, AKI di Indonesia masih tinggi dibandingkan dengan negara ASEAN lainnya. AKI di Indonesia meningkat dari 228/10.000 kelahiran pada tahun 2007 menjadi 359/100.000 Kelahiran Hidup (KH) pada tahun 2012. Pada tahun yang sama, Kementerian Kesehatan meluncurkan program Expanding Maternal and Neonatal Survival (EMAS) sebagai upaya untuk menurunkan angka kematian ibu dan neonatal sebesar $25 \%$. Namun upaya ini tidak berhasil seutuhnya, AKI di Indonesia pada tahun 2015 masih jauh dari target yang di tentukan yakni 305 kematian ibu per $10.000 \mathrm{KH}$, meskipun telah mengalami penurunan tapi tetap tidak mencapai target yang telah ditentukan (Pusdiknakes, 2016).

Penyebab tingginya angka kematian ibu di Indonesia disebabkan oleh beberapa faktor yaitu penyebab kematian lansung dan penyebab kematian tidak langsung. Lima penyebab angka kematian ibu terbesar yaitu perdarahan, hipertensi dalam kehamilan, 
abortus, partus lama/macet dan infeksi (Pusdiknakes, 2016).

Proses persalinan pada ibu bersalin normal berlangsung dalam waktu kurang dari 24 jam, dimana terbagi dalam empat kala. Kala I pada fase laten berlangsung selama delapan jam dan fase aktif berlangsung selama tujuh jam. Persalinan kala II biasanya berlangsung dua jam pada primi dan satu jam pada multigravida, kala III berlangsung kurang dari 30 menit sedangkan kala IV dimulai dari saat lahirnya plasenta sampai dua jam pertama post partum (Prawirohardjo, 2014).

Persalinan lama adalah persalinan yang berjalan lebih dari 24 jam untuk primigravida dan atau 18 jam untuk multigravida (Mochtar, 1998), masalah yang terjadi pada persalinan lama adalah fase laten lebih dari 8 jam. Persalinan telah berlangsung 12 jam atau lebih bayi belum lahir. Dilatasi serviks dikanan garis waspada pada persalinan fase aktif (Saifuddin, 2002). Menurut Manuaba (2008) persalinan lama pada kala II merupakan persalinan yang berlangsung lebih dari 2 jam pada primigravida dan lebih dari 1 jammultigravida. Faktor terjadinya proses persalinanyang lama dapat dipengaruhi oleh tiga hal yaitu tenaga, jalan lahir dan janin. Untuk faktor pada ibu sendiri akan dipengaruhi oleh umur, paritas dan kesiapan ibu dalam menghadapai persalinan. Lama persalinan tidak mudah ditentukan secara tepat karena permulaan persalinan sering tidak jelas dan bersifat subyektif. Dalam studi terhadap wanita, yang persalinannya mulai secara spontan, terdapat variasi yang luas untuk lama persalinan (Kuswanti, 2014).

Sampai saat ini yang dapat dikendalikan adalah masalah tenaga atau power, yaitu ditingkatkan dengan senam hamil. Senam atau latihan selama kehamilan memberikan efek positif terhadap pembukaan serviks dan aktivitas uterus yang terkoordinasi saat persalinan, juga ditemukan secara bermakna onset persalinan yang lebih awal dan lama persalinan yang lebih singkat dibandingkan dengan yang tidak melanjutkan senam hamil. Senam hamil dapat membantu persalinan sehingga ibu dapat melahirkan tanpa kesulitan, serta menjaga ibu dan bayi sehat setelah melahirkan (Ida, 2012).

Umur ibu hamil terhadap proses kala II persalinan sangat berpengaruh seperti lamanya tahapan kala II (proses pengeluaran bayi). Biasanya persalinan pada primitua dapat terjadi lebih lama, hal ini karena terjadi karena fungsi organ reproduksi sudah menurun. Sedangkan risiko kehamilan pada ibu yang terlalu muda biasanya timbul karena belum siap secara fisik maupun psikis.

Ibu yang telah melahirkan anak lebih dari 2 orang, lebih memiliki risiko untuk terjadi kala II lama. Sebab, pada saat kehamilan rahim ibu teregang oleh adanya janin, dan jika ibu sering melahirkan maka rahim akan semakin lemah. Ibu yang telah melahirkan 4 anak atau lebih dapat mengakibatkan kontraksi pada saat persalinan menjadi lemah, sehingga tidak terjadi kemajuan persalinan (Depkes RI, 2009). Oleh karena itu, ibu dengan paritas rendah akan lebih baik jika dibandingkan dengan ibu yang berparitas tinggi dalam kejadian kala II lama (Wiknjosastro, 2010).

Senam hamil adalah program kebugaran yang diperuntukkan bagi ibu hamil sehingga memiliki prinsip-prinsip gerakan khusus yang disesuaikan dengan kondisi ibu hamil. Latihan senam hamil dirancang khusus untuk menyehatkan dan membugarkan ibu hamil, mengurangi keluhan yang timbul selama kehamilan serta mempersiapkan fisik dan psikis ibu dalam 30 Jurnal Involusi Kebidanan, Vol. 6, No. 11, Januari 2016 menghadapi persalinan. Senam hamil biasanya dimulai saat kehamilan memasuki trimester ketiga, yaitu sekitar usia 28-30 minggu kehamilan (Ida,2012).

Berdasarkan latar belakang masalah diatas penulis tertarik untuk melakukan penelitian tentang "Hubungan Umur, Paritas, Berat Badan Lahir dan Senam Hamil dengan Lamanya Persalinan Kala II pada lbu Bersalin di Wilayah Kerja Puskesmas Samata dan Puskesmas Moncobalang Kabupaten Gowa".

\section{METODE PENELITIAN \\ Desain, Tempat, dan Waktu}

Jenis penelitian ini merupakan retrospektif kohort. Desain yang digunakan adalah cross sectional. Lokasi penelitian dilakukan di Puskesmas Moncobalang dan Puskesmas Samata Kabupatean Gowa mulai Maret-September 2020.

Jumlah dan Cara Pengambilan Subjek

Populasi dalam penelitian ini adalah semua ibu bersalin yang ada di Puskesmas Moncobalang dan Puskesmas Samata Kabupaten Gowa dalam setahun terakhir adalah 420 subjek. Teknik pengambilan 
sampel menggunakan teknik purposive sampling dengan besar sampel sebanyak 60 subjek.

\section{Jenis dan Cara Pengumpuan Data Instrumen penelitian yang digunakan dalam penelitian ini berupa lembar observasi.}

\section{Pengolahan dan Analisis Data}

Data diolah dengan editing, coding, data entry/ processing, cleaning data dengan program komputerisasi kemudian disajikan dalam bentuk tabel dan narasi. Dan dianalisis data yaitu analisis univariat, bivariat dan multivariat.

\section{HASIL}

\section{Analisis Univariat}

Berdasarkan kelompok umur responden, persentase tertinggi berada pada kelompok umur tidak berisiko atau usia ibu antara 20-35 tahun di Puskesmas Samata sebanyak 23 orang $(76,7 \%)$, begitupun di Puskesmas Moncobalang sebanyak 25 orang $(83,3 \%)$. Sedangkan persentase terendah berada pada kelompok umur berisiko atau usia ibu berada pada kelompok umur $<20$ tahun dan $>35$ tahun, di Puskesmas Samata sebanyak 7 orang $(23,3 \%)$ dan di Puskesmas Moncobalang sebanyak 5 orang $(16,7 \%)$.

Berdasarkan paritas ibu, persentase tertinggi adalah ibu multipara, di Puskesmas Samata sebanyak 21 orang $(70,3 \%)$ dan di Puskesmas Moncobalang sebanyak 18 orang $(80,0 \%)$. Sedangkan persentase terendah berada pada ibu primipara di Puskesmas Samata sebanyak 9 orang $(30,0 \%)$ dan di Puskesmas Moncobalang sebanyak 12 orang $(20,0 \%)$.

Berdasarkan berat badan lahir, persentase tertinggi berada pada ibu dengan berat badan lahir bayi 2500-4000 gram, di Puskesmas Samata sebanyak 27 orang $(90,0 \%)$ dan di Puskesmas Moncobalang sebanyak 24 orang (80\%). Sedangkan persentase terendah berada pada berat badan lahir bayi $<2500$ gram di Puskesmas Samata sebanyak 3 orang $(10,0 \%)$ dan di Puskesmas Moncobalang sebanyak 6 orang $(20,0 \%)$.

Berdasarkan pelaksanaan senam hamil, yang melaksanakan senam hamil adalah Puskesmas Samata sebanyak 30 orang $(100,0 \%)$ dan yang tidak melaksanakan senam hamil yaitu
Puskesmas Moncobalang sebanyak 30 orang $(100 \%)$.

Berdasarkan lamanya persalinan kala II, dengan persentase tertinggi adalah ibu yang lama kala II-nya normal, di Puskesmas Samata sebanyak 27 orang $(90,0 \%)$ dan di Puskesmas Moncobalang sebanyak 15 orang $(50,0 \%)$. Sedangkan persentase terendah adalah ibu yang lama kala II-nya lama yaitu di Puskesmas Samata sebanyak 3 orang $(10,0 \%)$ dan Puskesmas Moncobalang sebanyak 15 orang $(50,0 \%)$.

\section{Analisis Bivariat}

Hubungan umur dengan lamanya persalinan kala II, dari 60 responden di Puskesmas Samata dan Puskesmas Moncobalang, kelompok umur berisiko sebanyak 12 responden (100\%), yang kala II-nya normal sebanyak 8 responden $(66,7 \%)$ dan kala II-nya lama sebanyak 4 responden $(33,3 \%)$. Sedangkan kelompok umur tidak berisiko sebanyak 48 responden $(100,0 \%)$, yang kala II-nya normal sebanyak 34 responden $(70,8 \%)$ dan kala II-nya lama sebanyak 14 responden $(29,2 \%)$. Hasil Uji Chi-square nilai $p=0,079$, hasil probabilitas lebih besar dari taraf signifikan $5 \%$ $(0,079>0,05)$ artinya tidak ada hubungan umur dengan lamanya persalinan kala II pada ibu bersalin di Puskesmas Samata dan Puskesmas Moncobalang Kabupaten Gowa tahun 2020. Kemudian didapatkan nilai Relative Ratio $(R R)=1,143$ atau nilai $R R=1$, artinya umur ibu bukan merupakan faktor risiko cepatnya proses persalinan kala II pada ibu bersalin di Pusekesmas Samata dan Puskesmas Moncobalang Kabupaten Gowa tahun 2020.

Hubungan paritas dengan lamanya persalinan kala II, dari 60 responden di Puskesmas Samata dan Puskesmas Moncobalang, ibu primipara sebanyak 21 responden (100\%), yang kala II-nya normal sebanyak 10 responden $(47,6 \%)$ dan kala IInya lama sebanyak 11 responden $(55,0 \%)$. Sedangkan ibu multipara sebanyak 39 responden $(100,0 \%)$, yang kala II-nya normal sebanyak 32 responden $(82,1 \%)$ dan kala II-nya lama sebanyak 7 responden $(17,9 \%)$. Hasil Uji Chi-square nilai $p=0,006$, hasil probabilitas lebih kecil dari taraf signifikan $5 \% \quad(0,006<0,05)$ artinya ada hubungan paritas dengan lamanya persalinan kala II pada ibu bersalin di Puskesmas Samata dan Puskesmas Moncobalang Kabupaten Gowa tahun 2020. Kemudian didapatkan nilai Relative Ratio 
$(R R)=2,918$ atau nilai $R R=>1$, artinya ibu multipara 3 kali lipat lebih cepat proses persalinan kala II-nya daripada ibu primipara di Pusekesmas Samata dan Puskesmas Moncobalang Kabupaten Gowa tahun 2020.

Hubungan berat badan lahir dengan lamanya persalinan kala II, dari 60 responden di Puskesmas Samata dan Puskesmas Moncobalang, berat badan lahir rendah sebanyak 9 responden $(100 \%)$, yang kala II-nya normal sebanyak 6 responden $(66,7 \%)$ dan kala II-nya lama sebanyak 3 responden $(33,3 \%)$. Sedangkan berat badan lahir normal sebanyak 51 responden $(100,0 \%)$, yang kala II-nya normal sebanyak 36 responden $(70,6 \%)$ dan kala II-nya lama sebanyak 15 responden $(29,4 \%)$. Hasil Uji Chi-square nilai $p=0,813$, hasil probabilitas lebih besar dari taraf signifikan $5 \%$ $(0,813>0,05)$ artinya tidak ada hubungan berat badan lahir dengan lamanya persalinan kala II pada ibu bersalin di Puskesmas Samata dan Puskesmas Moncobalang Kabupaten Gowa tahun 2020. Kemudian didapatkan nilai Relative Ratio $(R R)=1,133$ atau nilai $R R=1$, artinya berat badan lahir bukan merupakan faktor risiko cepatnya proses persalinan kala II pada ibu bersalin di Pusekesmas Samata dan Puskesmas Moncobalang Kabupaten Gowa tahun 2020.

Hubungan senam hamil dengan lamanya kala II, dari 60 responden di Puskesmas Samata dan Puskesmas Moncobalang, yang melakukan senam hamil 30 responden $(100 \%)$, kala II-nya normal sebanyak 27 responden $(90,0 \%)$ dan kala II-nya lama sebanyak 3 responden $(10,0 \%)$. Sedangkan yang tidak melakukan senam hamil juga terdapat 30 responden $(100 \%)$, kala II-nya normal sebanyak 15 responden $(50,0 \%)$ dan kala II-nya lama sebanyak 15 responden $(50,0 \%)$. Hasil Uji Chi-square nilai $p=0,001$, hasil probabilitas lebih kecil dari taraf signifikan $5 \%$ $(0,001<0,05)$ artinya ada hubungan senam hamil dengan lamanya persalinan kala II pada ibu bersalin di Puskesmas Samata dan Puskesmas Moncobalang Kabupaten Gowa tahun 2020. Kemudiaan didapatkan nilai Relative Ratio $(\mathrm{RR})=5,000$ atau nilai $\mathrm{RR}=$ $>1$, artinya ibu yang melakukan senam hamil 5 kali lipat lebih cepat proses persalinan kala II-nya dari pada ibu yang tidak melakukan senam hamil pada ibu bersalin di Pusekesmas Samata dan Puskesmas Moncobalang Kabupaten Gowa tahun 2020.

\section{Analisis Multivariat}

Terdapat tiga variabel independen yang memiliki nilai $p<0,25$ yaitu umur, paritas dan senam hamil. Kemudian dilakukan pengeluaran variabel yang memiliki nilai $p>0,05$ yaitu umur. Selanjutnya variabel paritas dan senam hamil dimasukkan ke dalam pemodelan analisis multivariat dengan melihat nilai RR paling besar. Dapat disimpulkan bahwa variabel senam hamil merupakan variabel yang memiliki hubungan paling dominan dengan lamanya persalinan kala II pada ibu bersalin di Wilayah Kerja Puskesmas Moncobalang dan Puskesmas Samata Kabupaten Gowa tahun 2020.

\section{PEMBAHASAN}

Hubungan umur dengan lamanya persalinan kala II, diperoleh hasil Uji Chisquare dengan nilai $p=0,079$, hasil probabilitas lebih besar dari taraf signifikan $5 \%(0,079>0,05)$ artinya tidak ada hubungan umur dengan lamanya persalinan kala II pada ibu bersalin di Puskesmas Samata dan Puskesmas Moncobalang Kabupaten Gowa tahun 2020. Kemudian didapatkan nilai Relative Ratio $(R R)=1,143$ atau nilai $R R=1$, artinya umur ibu bukan merupakan faktor risiko cepatnya proses persalinan kala II pada ibu bersalin di Pusekesmas Samata dan Puskesmas Moncobalang Kabupaten Gowa tahun 2020.

Sejalan dengan penelitian yang dilakukan oleh Yusmaharani (2012), Hubungan Paritas dan Usia Ibu Bersalin dengan Kejadian Partus Lama di RSUD Arifin Achmad. Dimana $p$ value $=0,142$ $(0,142>0,05)$, artinya tidak ada hubungan antara usia ibu dengan kejadian partus lama.

Hasil penelitian ini juga sejalan dengan Handayani (2008), yang menyimpulkan bahwa tidak ada hubungan yang signifikan antara usia ibu dengan persalinan kala II lama, dengan menggunakan Uji Chi-square didapatkan nilai $p=0,199>0,05$.

Hasil penelitian ini sesuai dengan teori yang menyatakan bahwa penyebab utama partus lama bukan usia melainkan faktor-faktor lain seperti kelainan his yaitu dimana kontraksi uterus yang tidak terkoordinasi sehingga dapat menyebabkan pembukaan serviks tidak stabil dan dapat memperlambat pembukaan (Prawirohardjo, 2018). 
Menurut asumsi peneliti umur seorang ibu tidak berpengaruh terhadap lamanya kala II, karena banyak faktor lain yang dapat mempengaruhi seperti ibu yang tidak melakukan senam hamil, sehingga kelenturan otot-otot panggulnya tidak elastis dan dapat memicu terjadinya partus lama.

Walaupun tidak ada hubungan usia ibu bersalin dengan lamanya persalinan kala II hal itu tidak berarti faktor usia ibu tidak berpengaruh pada lamanya persalinan kala II, akan penyebab lamanya persalinan kala II sangat kompleks, sangat bergantung pada pengawasan sewaktu hamil, pertolongan persalinan yang baik dan penatalaksanaannya. Faktor-faktor penyebabnya antara lain karena kelainan letak janin, kelainan panggul, kelainan his, pimpinan partus yang salah, janin besar atau ada kelainan kongenital, grandemultipara dan ketuban pecah dini.

Hubungan paritas dengan lamanya persalinan kala II, diperoleh hasil Uji Chisquare dengan nilai $p=0,006$, hasil probabilitas lebih kecil dari taraf signifikan $5 \% \quad(0,006<0,05)$ artinya ada hubungan paritas dengan lamanya persalinan kala II pada ibu bersalin di Puskesmas Samata dan Puskesmas Moncobalang Kabupaten Gowa tahun 2020. Kemudian didapatkan nilai Relative Ratio $(\mathrm{RR})=2,918$ atau nilai $\mathrm{RR}=$ $>1$, artinya ibu multipara 3 kali lipat lebih cepat proses persalinan kala II-nya daripada ibu primipara di Pusekesmas Samata dan Puskesmas Moncobalang Kabupaten Gowa tahun 2020.

Penelitian ini sejalan dengan peneliti Destariyani (2016), tentang Faktor-faktor yang Berhubungan dengan Lama Kala II, menunjukkan ada hubungan yang bermakna antara paritas dengan kala II lama, hasil uji statistik menunjukkan nilai $p=$ $0,000<\alpha=0,05$.

Menurut hasil penelitian Supriyanti (2001), menunjukkan bahwa ada hubungan yang bermakna antara paritas dengan distosia persalinan. Ibu hamil dengan paritas satu atau lebih dari lima memiliki risiko 3,86 kali lebih besar dibandingkan dengan ibu hamil dengan paritas dua sampai lima. Penelitian juga didapatkan bahwa sebagian kecil $(13 \%)$ ibu bersalin multipara juga mengalami kala II lama. Hal ini terjadi karena ada faktor lain yang mempengaruhi lama persalinan kala II yaitu interval kelahiran, ketuban pecah dini, penolong persalinan dan psikis ibu.
Hasil penelitian ini sesuai dengan hasil penelitian yang dilakukan oleh Fideria (2011), yang menyimpulkan ada hubungan paritas dengan persalinan kala II lama. Teori yang dikemukakan oleh Cunning Cam (2019) menyatakan bahwa wanita dengan paritas tinggi berisiko mengalami persalinan lama karena disebabkan uterus mengalami kekendoran pada dinding rahim.

Hubungan berat badan lahir dengan lamanya persalinan kala II, diperoleh hasil Uji Chi-square dengan nilai $p=0,813$, hasil probabilitas lebih besar dari taraf signifikan $5 \%(0,813>0,05)$ artinya tidak ada hubungan berat badan lahir dengan lamanya persalinan kala II pada ibu bersalin di Puskesmas Samata dan Puskesmas Moncobalang Kabupaten Gowa tahun 2020. Kemudian didapatkan nilai Relative Ratio $(R R)=1,133$ atau nilai $R R=1$, artinya berat badan lahir bukan merupakan faktor risiko cepatnya proses persalinan kala II pada ibu bersalin di Pusekesmas Samata dan Puskesmas Moncobalang Kabupaten Gowa tahun 2020.

Sejalan dengan penelitian yang dilakukan oleh Destariyani (2016), ada hubungan berat badan janin dengan kala II lama, nilai $p=0,000<\alpha=0,05$. Janin yang mempunyai berat lebih 4000 gram memiliki kesukaran yang ditimbulkan dalam persalinan karena besarnya kepala atau besarnya bahu. Bagian paling keras dan besar dari janin adalah kepala, sehingga besarnya kepala janin mempengaruhi berat badan janin.

Penelitian ini sejalan dengan Yohanna (2016), yang menyatakan ada hubungan antara janin besar dengan kejadian partus lama di Rumah Sakit Umum Daerah Dr. H. Abdul Moelek Provinsi Lampung. Hasil Uji Chi-square diperoleh nilai $p$ value $0,001<\alpha=0,05$ dengan nilai $\mathrm{OR}=2,427$, yang artinya ibu yang mempunyai janin besar mempunyai risiko 2,427 kali lebih besar untuk mengalami kejadian persalinan lama.

Penelitian ini juga sejalan dengan Hastati (2011), menyebutkan bahwa ada hubungan yang signifikan antara berat badan janin dengan lamanya kala II pada ibu bersalin primiparitas dan pada multiparitas. Berat badan janin $>3000$ gram merupakan salah satu faktor risiko terjadinya lama kala II pada proses persalinan. Multiparitas dengan berat badan janin $>3000$ gram merupakan salah satu faktor risiko kala II lama. 
Hubungan senam hamil dengan lamanya persalinan kala II, diperoleh hasil Uji Chi-square nilai $p=0,001$, hasil probabilitas lebih kecil dari taraf signifikan $5 \% \quad(0,001<0,05)$ artinya ada hubungan senam hamil dengan lamanya persalinan kala II pada ibu bersalin di Puskesmas Samata dan Puskesmas Moncobalang Kabupaten Gowa tahun 2020. Kemudiaan didapatkan nilai Relative Ratio (RR) $=5,000$ atau nilai $R R=>1$, artinya ibu yang melakukan senam hamil 5 kali lipat lebih cepat proses persalinan kala II-nya dari pada ibu yang tidak melakukan senam hamil pada ibu bersalin di Pusekesmas Samata dan Puskesmas Moncobalang Kabupaten Gowa tahun 2020.

Penelitian ini sejalan dengan penelitian yang dilakukan oleh Juita, dkk (2017), yang menyatakan ada pengaruh senam hamil dengan lamanya persalinan kala II di BPM Dince Safrina Pekan Baru dengan $p$ value adalah 0,002 . Diperoleh hasil bahwa mayoritas ibu yang melakukan senam hamil lama persalinan kala II berlangsung dalam kategori cepat sebesar $90 \%$ sedangkan dalam kategori normal hanya $10 \%$.

Penelitian ini juga sejalan dengan penelitian yang dilakukan oleh Dewi dan Novita (2018), ada hubungan pelaksanaan senam hamil dengan lama persalinan kala II pada ibu primigravida di Wilayah Kerja Puskesmas Padangmatinggi Kota Padangsisimpuan dengan nilai $p=0,001$. Hal ini terlihat bahwa pelaksanaan senam hamil sangat mempengaruhi lamanya proses persalinan.

Peneliti berasumsi bahwa senam hamil berpengaruh pada proses persalinan yaitu untuk melatih otot-otot yang berperan dalam persalinan serta teknik-teknik mengejan dan relaksasi. Otot yang terlatih akan memiliki kekuatan dan tonus yang baik dan dipadu dengan teknik mengejan yang baik, wanita hamil akan melewati proses melahirkan dengan waktu yang lebih cepat, dengan demikian bayinya akan lebih cepat melewati jalan lahir dan risiko bantuan alat seperti vakum dan forcep lebih kecil. Hal ini sependapat dengan Supriatmaja dan Suwardewa (2005), yang membuktikan bahwa kelompok ibu yang melakukan senam hamil menjalani proses persalinan kala II lebih cepat dibandingkan kelompok ibu yang tidak melakukan senam hamil dan insiden partus lama pada kelompok perlakuan (senam hamil) lebih kecil dibandingkan dengan kelompok kontrol (tidak senam hamil).

Lamanya proses persalinan dapat dipengaruhi oleh tiga hal yaitu tenaga, jalan lahir dan janin. Sampai saat ini yang dapat dikendalikan adalah masalah tenaga atau power pada ibu, yaitu dapat ditingkatkan salah satunya dengan senam hamil. Senam hamil yang akan diterapkan, bukan senam yang berorientasi sebatas pada kebugaran tubuh saja. Melainkan untuk memperkuat otot, melenturkan persendian dan dapat melatih konsentrasi agar bisa mengalihkan pikiran sehingga bisa melupakan rasa sakit saat melahirkan. Metode ini terbukti cukup berhasil untuk membantu meringankan proses persalinan. Di samping itu, rasa nyeri saat proses persalinan dapat berlangsung lebih minimal, dengan jalan mengatur pernafasan, berkonsentrasi dan mengalihkan pikiran, sehingga dengan sendirinya stres saat melahirkan bisa dikurangi. Maka proses persalinan dapat berjalan lebih mulus dan singkat (Mulyata, 2010).

Senam atau latihan selama kehamilan memberikan efek positif terhadap pembukaan serviks dan aktifitas uterus yang terkoordinasi saat persalinan, Berdasarkan hasil penelitian Nur, Sutaryono dan Sri (2016) diperoleh bahwa senam hamil berpengaruh terhadap lamanya proses persalinan. Hal ini terlihat dari hasil penelitian yaitu responden yang melaksanakan senam hamil cenderung mengalami proses persalinan kala I dan kala II yang cepat sebanyak 12 responden $(27,3 \%)$ sedangkan responden yang tidak melaksanakan senam hamil cenderung mengalami persalinan lama sebanyak 18 responden $(40,9 \%)$.

Senam hamil merupakan salah satu bentuk olahraga untuk membantu ibu mendapatkan tenaga persalinan yang baik dan adekuat sehingga dapat memperlancar proses persalinan. Melalui senam hamil diharapkan persalinan berjalan secara normal, dapat mengurangi rasa sakit dan ibu tidak merasa takut serta mempunyai kepercayaan diri yang mantap saat menjalani proses persalinan dan kelahiran.

\section{SARAN}

Bagi ibu hamil di Puskesmas Samata agar tetap melaksanakan senam hamil di rumah di tengah Pandemi Covid-19 ini. Dan untuk ibu hamil di Puskesmas Moncobalang Kabupaten Gowa agar ikut 
serta melaksanakan senam ibu hamil di rumah dengan melihat vidio di Youtube.

Bagi tempat peneliti, diharapkan kepada Kepala Puskesmas Samata dan bidan pelaksana program untuk memberikan HE kepada ibu hamil tentang faktor-faktor yang menyebabkan lamanya persalinan khususnya pada kala II. Diharapkan kepada Kepala Puskesmas Samata dan bidan pelaksana program senam hamil dapat mempertahankan senam ibu hamil yang telah dilakukan dan kepada Kepala Puskesmas Moncobalang dan Bidan Koordinator KIA agar dapat melaksanakan kegiatan senam ibu hamil.

Bagi institusi, hasil penelitian ini diharapkan agar dapat digunakan sebagai bahan referensi (kepustakaan) dan sarana penelitian yang akan datang.

Bagi peneliti selanjutnya, diharapkan kepada peneliti lain agar bisa melanjutkan penelitian ini terhadap dengan menabahkan beberapa variabel atau menggunakan variabel yang berbeda. Diharapkan kepada peneliti lain agar bisa melanjutkan penelitian senam hamil ini terhadap variabel yang berbeda misalnya senam hamil terhadap nyeri punggung, pola tidur ibu hamil dan nyeri persalinan.

\section{UCAPAN TERIMA KASIH}

Penulis mengucakan terima kasih dan penghargaan kepada Dipa Poltekes, Politeknik Kesehatan Kemenkes RI Makassar Jurusan Kebidanan, Puskesmas Moncobalang dan Puskesmas Samata Kabupaten Gowa yang telah mengizinkan melakukan penelitian dengan hasil yang dapat digunakan untuk publikasi bersama.

\section{DAFTAR PUSTAKA}

Cunningham, dkk, 2006. Obstetri Williams (Edisi 21), Jilid Pertama. Jakarta: EGC.

Dewi, Sri S. dan Novita Sari B. 2018. Hubungan Pelaksanaan Senam Hamil dengan Lama Persalinan Kala II pada Ibu Primigravida di Wilayah Kerja Puskesma Padangmatinggi Kota Padangsidimpuan Vol. 3 No. 2. (Online) jurnal.stikesaufa.ac.id/index.php/health/article/vie w/52/28 diakses tanggal 09 Oktober 2020.

Depkes RI. 2008. Asuhan Persalinan Normal. Jakarta : JNPK-KR. 2013. Buku Profil Kesehatan Provinsi Jawa
Tengah Tahun 2012. Dinas Kesehatan Provinsi Jawa Tengah

Fraser, M Diane., dan Margaret A. Cooper, 2011. Myles Buku Ajar Bidan (Edisi 14). Jakarta: EGC.

Ida. 2012. Senam Hamil. (Online) http://www.mediabangsa.com/home/ 112- kehamilan/572-senamhamil.pdf. tanggal akses 10 April 2019.

Juita, dkk. 2017. Pengaruh Senam Hamil dengan Lamanya Persalinan Kala I dan Kala II di BPM Dince Safrina Pekan Baru. (Online) http://jurnal.pkr.ac.id/index.php/JIA/ar ticle.donwload/9/8/ diakses tanggal 09 Oktober 2020.

Kuswanti, Ina. 2014. Asuhan Kehamilan. Yogyakarta: PT Pustaka Pelajar.

Lestari, T. 2015. Kumpulan Teori Untuk Kajian Pustaka Penelitian Kesehtan. Yogyakarta: Nuha Medika.

Machfoedz, Ircham. 2012. Biostatika. Yogyakarta: Fitramaya.

Maulana, H. D. 2013. Promosi Kesehatan. Jakarta: Buku Kedokteran EGC.

Manuaba C. 2009. Memahami Kesehatan Reproduksi Wanita. Buku Kedokteran Jakarta: EGC.

Manuaba, I. B. G. 2010. Ilmu Kebidanan, Penyakit Kandungan, dan KB edisi 2. Jakarta

Marmi. Rahardjo, K. 2012. Asuhan Neonatus, Bayi, Balita, dan Anak Pra Sekolah.

Yogyakarta: Pustaka PelajarMulyata. 2010. Paket Penyuluhan Kognitif dan Senam Persalinan pada Prmigravida, Mengurangi Cemas dan Nyeri Persalinan. (Online) http// Unair. Ac.id / go. diakses pada tanggal 09 Oktober 2020.

Nur, Sutaryono dan Sri Lestari. Hubungan Senam Hamil terhadap Lamanya Proses Persalinan pada Ibu Bersalin di Wilayah Kerja Puskesmas Bayat Klaten. Jurnal Involusi Kebidanan Vol. 6 No.11.

Notoatmodjo, S. 2012. Promosi Kesehatan dan Perilaku Kesehatan. Jakarta: Rineka Cipta Rahmawati.

Pusdiknakes. 2016. Buku Ajar Imunisasi. (E. Mulati, R. Isfan, \& O. F. Royati, Eds.). Jakarta: Kemenkes RI. Retrieved from

http://www.pdpersi.co.id/pusdiknakes 
Prawirohardjo, S. 2012. Ilmu Kebidanan. Jakarta: PT. Bina Pustaka Sarwono Prawirohardjo.

Riana. 2008. Pengaruh Senam Hamil terhadap Lama Persalinan Kala II pada Ibu Bersalin Primigravida di Wilayah Kerja Puskesmas Cilimus Kabupaten Kuningan. Banyumas: Universitas Bina Indonesia.

Rukiyah Y. 2016. Asuhan Kebidanan Kehamilan berdasarkan Kurikulum Berbasis Kompetensi. Jakarta: Trans Info Media.

Salmah dkk. 2006. Asuhan Kebidanan Antenatal. Buku Kedokteran. Jakarta: EGC.

Sugiyono. 2010. Metode Penelitian Administrasi. Alfabeta: Bandung. Sugiyono. 2014. Metode Penelitian Kuantitatif, Kualitatif, dan RAD. Bandung: CV. Alfabeta.
Supriatmaja dan Suwardewa. 2005. Pengaruh Senam Hamil terhadap Persalinan Kala I dan Kala II, Bagian IImu Kebidanan dan Penyakit Kandungan FK UNUD/ RS Sanglah Denpasar. (Online) www.journal.unud.ac.id diakses pada tanggal 09 Oktober 2020.

Sostroasmoro, Sudigdo dan Sofyan Ismal. 2014. Dasar-dasar Metodologi Penelitian Klinis Edisi ke-5. Jakarta: Sagung Seto.

Utami wahyu. 2015. Pengaruh Umur Ibu, Paritas, Usia Kehamilan, Berat Badan Lahirbayi Terhadap Asfiksia Bayi Pada Ibua Pre Eklamsia Berat di RS Permata Bunda Purwodadi (Online) http://eprints.uns.ac.id/id/epirint/2026 6 diakses pada tanggal 7 November 2020. 
Tabel 5.1

Distribusi frekuensi umur responden di Puskesmas Samata dan Puskesmas Moncobalang Kabupaten Gowa tahun 2020

\begin{tabular}{ccccccc}
\hline \multirow{2}{*}{ Umur } & \multicolumn{2}{c}{ Samata } & \multicolumn{2}{c}{ Moncobalang } & \multicolumn{2}{c}{ Total } \\
\cline { 2 - 7 } & $\mathbf{F}$ & $\mathbf{\%}$ & $\mathbf{F}$ & $\mathbf{\%}$ & $\mathbf{F}$ & $\mathbf{\%}$ \\
\hline Berisiko & 7 & 23,3 & 5 & 16,7 & 12 & 20,0 \\
Tidak Berisiko & 23 & 76,7 & 25 & 83,3 & 48 & 80,0 \\
& & & & & & \\
\hline Total & $\mathbf{3 0}$ & $\mathbf{1 0 0 , 0}$ & $\mathbf{3 0}$ & $\mathbf{1 0 0 , 0}$ & $\mathbf{6 0}$ & $\mathbf{1 0 0 , 0}$ \\
\hline
\end{tabular}

Sumber: Data Primer 2020

Tabel 5.2.

Distribusi frekuensi paritas responden di Puskesmas Samata dan Puskesmas Moncobalang Kabupaten Gowa tahun 2020

\begin{tabular}{ccccccc}
\hline \multirow{2}{*}{ Paritas } & \multicolumn{2}{c}{ Samata } & \multicolumn{2}{c}{ Moncobalang } & \multicolumn{2}{c}{ Total } \\
\cline { 2 - 7 } & $\mathbf{F}$ & $\mathbf{\%}$ & $\mathbf{F}$ & $\mathbf{\%}$ & $\mathbf{F}$ & $\mathbf{\%}$ \\
\hline Primipara & 9 & 30,0 & 12 & 20,0 & 21 & 35,0 \\
Multipara & 21 & 70,3 & 18 & 80,0 & 39 & 65,0 \\
& & & & & & \\
\hline Total & $\mathbf{3 0}$ & $\mathbf{1 0 0 , 0}$ & $\mathbf{3 0}$ & $\mathbf{1 0 0 , 0}$ & $\mathbf{6 0}$ & $\mathbf{1 0 0 , 0}$ \\
\hline
\end{tabular}

Sumber: Data Primer 2020

Tabel 5.3.

Distribusi frekuensi berat badan lahir di Puskesmas Samata dan Puskesmas Moncobalang Kabupaten Gowa tahun 2020

\begin{tabular}{ccccccc}
\hline \multirow{2}{*}{ BBL } & \multicolumn{2}{c}{ Samata } & \multicolumn{3}{c}{ Moncobalang } & \multicolumn{2}{c}{ Total } \\
\cline { 2 - 7 } & $\mathbf{F}$ & $\mathbf{\%}$ & $\mathbf{F}$ & $\mathbf{\%}$ & $\mathbf{F}$ & $\mathbf{\%}$ \\
\hline BBLR & 3 & 10,0 & 6 & 20,0 & 9 & 15,0 \\
Normal & 27 & 90,0 & 24 & 80,0 & 51 & 85,3 \\
& & & & & & \\
\hline Total & $\mathbf{3 0}$ & $\mathbf{1 0 0 , 0}$ & $\mathbf{3 0}$ & $\mathbf{1 0 0 , 0}$ & $\mathbf{6 0}$ & $\mathbf{1 0 0 , 0}$ \\
\hline
\end{tabular}

Sumber: Data Primer 2020

Tabel 5.4 .

Distribusi frekuensi pelaksanaan senam hamil di Puskesmas Samata dan Puskesmas Moncobalang Kabupaten Gowa tahun 2020

\begin{tabular}{ccccccc}
\hline Senam Hamil & \multicolumn{2}{c}{ Samata } & \multicolumn{2}{c}{ Moncobalang } & \multicolumn{2}{c}{ Total } \\
\cline { 2 - 7 } & $\mathbf{F}$ & $\mathbf{\%}$ & $\mathbf{F}$ & $\mathbf{\%}$ & $\mathbf{F}$ & $\%$ \\
\hline Melakukan & 30 & 100,0 & 0 & 0,0 & 30 & 50,0 \\
senam hamil & 0 & 0,0 & 30 & 100,0 & 30 & 50,0 \\
$\begin{array}{c}\text { Tidak senam } \\
\text { hamil }\end{array}$ & & & & & & \\
\hline Total & $\mathbf{3 0}$ & $\mathbf{1 0 0 , 0}$ & $\mathbf{3 0}$ & $\mathbf{1 0 0 , 0}$ & $\mathbf{6 0}$ & $\mathbf{1 0 0 , 0}$ \\
\hline
\end{tabular}

Sumber: Data Primer 2020 
Tabel 5.5.

Distribusi frekuensi lama persalinan kala II di Puskesmas Samata dan Puskesmas Moncobalang Kabupaten Gowa tahun 2020

\begin{tabular}{ccccccc}
\hline Lama & \multicolumn{2}{c}{ Samata } & \multicolumn{2}{c}{ Moncobalang } & \multicolumn{2}{c}{ Total } \\
\cline { 2 - 7 } $\begin{array}{c}\text { Persalinan Kala } \\
\text { II }\end{array}$ & $\mathbf{F}$ & $\mathbf{\%}$ & $\mathbf{F}$ & $\mathbf{\%}$ & $\mathbf{F}$ & $\mathbf{\%}$ \\
\hline Lama & 3 & 90,0 & 15 & 50,0 & 18 & 30,0 \\
Normal & 27 & 10,0 & 15 & 50,0 & 42 & 70,0 \\
\hline Total & $\mathbf{3 0}$ & $\mathbf{1 0 0 , 0}$ & $\mathbf{3 0}$ & $\mathbf{1 0 0 , 0}$ & $\mathbf{6 0}$ & $\mathbf{1 0 0 , 0}$ \\
\hline
\end{tabular}

Sumber: Data Primer

Tabel 5.6.

Hubungan umur dengan lamanya persalinan kala II pada ibu bersalin di Puskesmas Samata dan Puskesmas Moncobalang Kabupaten Gowa tahun 2020

\begin{tabular}{|c|c|c|c|c|c|c|c|c|}
\hline \multirow{3}{*}{ Umur } & \multicolumn{4}{|c|}{ Lama Persalinan Kala II } & \multirow{2}{*}{\multicolumn{2}{|c|}{ Total }} & \multirow{3}{*}{ Nilai $p$} & \multirow{3}{*}{ Nilai RR } \\
\hline & \multicolumn{2}{|c|}{ Normal } & \multicolumn{2}{|c|}{ Lama } & & & & \\
\hline & $\mathbf{F}$ & $\%$ & $\mathbf{F}$ & $\%$ & $\mathbf{F}$ & $\%$ & & \\
\hline Berisiko & 8 & 66,7 & 4 & 33,3 & 12 & $\begin{array}{c}100 \\
0\end{array}$ & & \\
\hline $\begin{array}{c}\text { Tidak } \\
\text { Berisiko }\end{array}$ & 34 & 70,8 & 14 & 29,2 & 48 & $\begin{array}{c}100 \\
0\end{array}$ & 0,079 & 1,143 \\
\hline Total & 42 & 70,0 & 18 & 30,0 & 60 & $\begin{array}{c}100 \\
\%\end{array}$ & & \\
\hline
\end{tabular}

Sumber: Data Primer 2020

Tabel 5.7 .

Hubungan paritas dengan lamanya persalinan kala II pada ibu bersalin di Puskesmas Samata dan Puskesmas Moncobalang Kabupaten Gowa tahun 2020

\begin{tabular}{|c|c|c|c|c|c|c|c|c|}
\hline \multirow{3}{*}{ Paritas } & \multicolumn{4}{|c|}{ Lama Persalinan Kala II } & \multirow{2}{*}{\multicolumn{2}{|c|}{ Total }} & \multirow{3}{*}{ Nilai $p$} & \multirow{2}{*}{ Nilai RR } \\
\hline & \multicolumn{2}{|c|}{ Normal } & \multicolumn{2}{|c|}{ Lama } & & & & \\
\hline & $\mathbf{F}$ & $\%$ & $\mathbf{F}$ & $\%$ & $\mathbf{F}$ & $\%$ & & \\
\hline Primipara & 10 & 47,6 & 11 & 52,4 & 21 & $\begin{array}{c}100 \\
0\end{array}$ & & \\
\hline Multipara & 32 & 82,1 & 7 & 17,9 & 39 & $\begin{array}{c}100 \\
0\end{array}$ & 0,006 & 2,918 \\
\hline Total & 42 & 70,0 & 18 & 30,0 & 60 & $\begin{array}{c}100 \\
\%\end{array}$ & & \\
\hline
\end{tabular}

Sumber: Data Primer 2020 
Tabel 5.8.

Hubungan berat badan lahir dengan lamanya persalinan kala II pada ibu bersalin di Puskesmas Samata dan Puskesmas Moncobalang Kabupaten Gowa tahun 2020

\begin{tabular}{|c|c|c|c|c|c|c|c|c|}
\hline \multirow{3}{*}{ BBL } & \multicolumn{4}{|c|}{ Lama Persalinan Kala II } & \multirow{2}{*}{\multicolumn{2}{|c|}{ Total }} & \multirow{3}{*}{ Nilai $p$} & \multirow{3}{*}{ Nilai RR } \\
\hline & \multicolumn{2}{|c|}{ Normal } & \multicolumn{2}{|c|}{ Lama } & & & & \\
\hline & $\mathbf{F}$ & $\%$ & $\mathbf{F}$ & $\%$ & $\mathbf{F}$ & $\%$ & & \\
\hline BBLR & 6 & 66,7 & 3 & 33,3 & 9 & $\begin{array}{c}100 \\
0\end{array}$ & & \\
\hline Normal & 36 & 70,6 & 15 & 29,4 & 51 & $\begin{array}{c}100 \\
0 \\
\end{array}$ & 0,813 & 1,133 \\
\hline Total & 42 & 70,0 & 18 & 30,0 & 60 & $\begin{array}{c}100 \\
\%\end{array}$ & & \\
\hline
\end{tabular}

Sumber: Data Primer 2020

Tabel 5.9.

Hubungan senam hamil dengan lamanya persalinan kala II pada ibu bersalin di Puskesmas Samata dan Puskesmas Moncobalang Kabupaten Gowa tahun 2020

\begin{tabular}{|c|c|c|c|c|c|c|c|c|}
\hline \multirow{3}{*}{$\begin{array}{c}\text { Senam } \\
\text { Hamil }\end{array}$} & \multicolumn{4}{|c|}{ Lama Persalinan Kala II } & \multirow{2}{*}{\multicolumn{2}{|c|}{ Total }} & \multirow{3}{*}{ Nilai $p$} & \multirow{3}{*}{ Nilai $\mathbf{R} R$} \\
\hline & \multicolumn{2}{|c|}{ Normal } & \multicolumn{2}{|c|}{ Lama } & & & & \\
\hline & $\mathbf{F}$ & $\%$ & $\mathbf{F}$ & $\%$ & $\mathbf{F}$ & $\%$ & & \\
\hline Senam Hamil & 27 & 90,0 & 3 & 10,0 & 30 & $\begin{array}{c}100 \\
0\end{array}$ & & \\
\hline $\begin{array}{c}\text { Tidak Senam } \\
\text { Hamil }\end{array}$ & 15 & 50,0 & 15 & 50,0 & 30 & $\begin{array}{c}100 \\
0\end{array}$ & 0,001 & 5,000 \\
\hline Total & 42 & 70,0 & 18 & 30,0 & 60 & $\begin{array}{c}100 \\
\%\end{array}$ & & \\
\hline
\end{tabular}

Sumber: Data Primer 2020

Tabel 5.10.

Seleksi I Kandidat Analisis Multivariat Berdasarkan Hasil Analisis Bivariat

\begin{tabular}{lccc}
\hline \multicolumn{1}{c}{ Variabel } & $\boldsymbol{p}$ & $\mathbf{R R}$ & $\mathbf{9 5 \%} \mathbf{C l}$ \\
\hline Umur & 0,079 & 1,143 & $(0,458-2,849)$ \\
Paritas & 0,006 & 2,918 & $(1,331-6,400)$ \\
Berat Badan Lahir & 0,813 & 1,133 & $(0,410-3,314)$ \\
Senam Hamil & 0,001 & 5,000 & $(1,613-15,503)$ \\
\hline
\end{tabular}

Sumber: Data Primer, 2020

Tabel 5.11.

Seleksi II Kandidat Analisis Multivariat Berdasarkan Hasil Analisis Bivariat

\begin{tabular}{lccc}
\hline \multicolumn{1}{c}{ Variabel } & $\boldsymbol{p}$ & RR & $\mathbf{9 5 \%} \mathbf{C l}$ \\
\hline Umur & 0,079 & 1,143 & $(0,458-2,849)$ \\
Paritas & 0,006 & 2,918 & $(1,331-6,400)$ \\
Senam Hamil & 0,001 & 5,000 & $(1,613-15,503)$ \\
\hline
\end{tabular}

Sumber: Data Primer, 2020 
Tabel 5.12 .

Seleksi III Kandidat Analisis Multivariat Berdasarkan Hasil Analisis Bivariat

\begin{tabular}{lccc}
\hline \multicolumn{1}{c}{ Variabel } & $\boldsymbol{p}$ & $\mathbf{R R}$ & $\mathbf{9 5 \%} \mathbf{C l}$ \\
\hline Paritas & 0,006 & 2,918 & $(1,331-6,400)$ \\
Senam Hamil & 0,001 & 5,000 & $(1,613-15,503)$ \\
\hline Sumber: Data Primer, 2020 & & &
\end{tabular}

